\title{
Disabling Vertigo and Tinnitus Caused by Intrameatal Compression of the Anterior Inferior Cerebellar Artery on the Vestibulocochlear Nerve: A Case Report, Surgical Considerations, and Review of the Literature
}

\author{
Hamid Borghei-Razavi ${ }^{1} \quad$ Omid Darvish ${ }^{1} \quad$ Uta Schick $^{1}$ \\ ${ }^{1}$ Department of Neurosurgery, Clemens Hospital, Münster, Germany \\ J Neurol Surg Rep 2014;75:e47-e51. \\ Address for correspondence Hamid Borghei-Razavi, MD, Department of \\ Neurosurgery, Clemens Hospital, Academic Hospital of Münster University, \\ Münster, Germany, Düesbergweg 124, 48153 Münster, Germany \\ (e-mail: Shbr61@yahoo.com; h.borghei-razavi@clemenshospital.de).
}

\begin{abstract}
Microvascular compression of the vestibulocochlear nerve is known as a cause of tinnitus and vertigo in the literature, but our review of the literature shows that the compression is usually located in the cerebellopontine angle and not intrameatal.

We present a case of intrameatal compression of the anterior inferior cerebellar artery (AICA) on the vestibulocochlear nerve of a 40-year-old woman with symptoms of disabling vertigo and intermittent high-frequency tinnitus on the left side without any hearing loss for $\sim 4$ years. Magnetic resonance imaging of the brain did not show any abnormality, but magnetic resonance angiography showed a left intrameatal AICA loop as a possible cause of the disabling symptoms. After the exclusion of other possible reasons for disabling vertigo, surgery was indicated. The intraoperative findings proved the radiologic findings. The large AICA loop was found extending into the internal

Keywords

- anterior inferior cerebellar artery

- microvascular decompression

- vertigo

- internal auditory canal auditory canal and compressing the vestibulocochlear nerve. The AICA loop was mobilized and separated from the vestibulocochlear nerve.

The patient's symptoms resolved immediately after surgery, and no symptoms were noted during 2 years of follow-up in our clinic. Her hearing was not affected by the surgery. In addition to other common reasons, such as acoustic neuroma, disabling vertigo and tinnitus can occur from an intrameatal arterial loop compression of the vestibulocochlear nerve and may be treated successfully by drilling the internal acoustic meatus and separating the arterial conflict from the vestibulocochlear nerve.
\end{abstract}

\section{Introduction}

The neurovascular compression of the fifth and seventh cranial nerves is known as the cause of trigeminal neuralgia (TN) and hemifacial spasm. The rate of success of surgical decompression for these two syndromes is satisfactory. ${ }^{1,2}$ However, it is still difficult to consider neurovascular compression of the eighth cranial nerve as a major cause of disabling vertigo and tinnitus. ${ }^{3}$
In the last decade, microvascular decompression (MVD) of the vestibulocochlear nerve was reported as an efficient treatment option with a high rate of success (up to 80\%) for several vestibulocochlear compression syndromes. ${ }^{4-6}$

As an anatomical consideration, vascular anomalies may cause compression at the root entry or exit zone of the cranial nerves. ${ }^{7}$ In contrast to TN, which almost always results from a compression at the nerve root entry zone, vestibulocochlear received

February 28, 2013

accepted after revision

September 17, 2013

published online

December 12, 2013
DOI http://dx.doi.org/

10.1055/s-0033-1359299. ISSN 2193-6358. (c) 2014 Georg Thieme Verlag KG
Stuttgart · New York

License terms

(c) $(1) \$$ 
compression syndrome results from the nerve's conflict over its entire segment in the cerebellopontine angle. ${ }^{8}$

Although a loop of the anterior interior cerebellar artery (AICA) can frequently lead to the dislocation and compression of the eighth cranial nerve at the cerebellopontine angle, ${ }^{9}$ the intracanalicular neurovascular compression of the vestibulocochlear nerve has been reported in only two cases $^{8,10}$ (-Table 1).

We present an unusual case of an intrameatal AICA loop compressing the vestibulocochlear nerve in a patient who developed the symptoms of disabling vertigo and tinnitus without a unilateral hearing loss, and we also consider the surgical issues.

\section{Case Presentation}

A 40-year-old woman was admitted to our clinic with a 4-year history of recurrent vertigo and nonpulsatile tinnitus in the left ear, along with left-sided aural fullness without any hearing loss. The episodes of vertigo lasted up to 2 hours (which was workload dependent and not positional) and had significantly impaired the patient's ability to work for the past 2 years. The tinnitus episodes did not have any relationship to the vertigo.

During the physical examination, the patient was not hypertensive. Her neurologic examination was normal. A preoperative auditory brainstem response (ABR) examination showed latency of wave I and III brainstem potentials. A caloric test was bilaterally normal. Videonystagmography and posturography did not show any abnormalities. A balance examination of the patient did not show any imbalance tendencies to the right or the left, even though she had complained about subjective disequilibrium that was noted in her medical record.

Further medical treatment of the condition including intravenous infusions according to the protocol proposed by Stennert $^{10,11}$ did not show any improvement. The vestibulocochlear signs and symptoms were refractive to a high-dose carbamazepine therapy. Due to the unfavorable results of the primary neurotologic examinations, the patient additionally underwent magnetic resonance imaging (MRI) (-Fig. 1).

The MRI did not show any pathologic findings, but an additional magnetic resonance angiography (MRA) examination revealed a loop of the AICA extending into the left internal auditory meatus (-Fig. 2 ).

After a long discussion with the patient about the relative indication of vestibulocochlear decompression and explaining the details of our experiences as well as the surgical risks, the patient decided to go ahead with the operation due to the

Table 1 Two cases of intrameatal vascular compression resulting in vestibulocochlear compression

\begin{tabular}{|l|l|l|}
\hline Study & Presentation & Vascular reason \\
\hline Wuertenberger et $\mathrm{al}^{8}$ & $\begin{array}{l}\text { Vertigo and } \\
\text { tinnitus }\end{array}$ & $\begin{array}{l}\text { Intrameatal venous } \\
\text { compression }\end{array}$ \\
\hline De Ridder et a $1^{10}$ & $\begin{array}{l}\text { Pulsatile } \\
\text { tinnitus }\end{array}$ & $\begin{array}{l}\text { Intrameatal arterial } \\
\text { contact }\end{array}$ \\
\hline
\end{tabular}

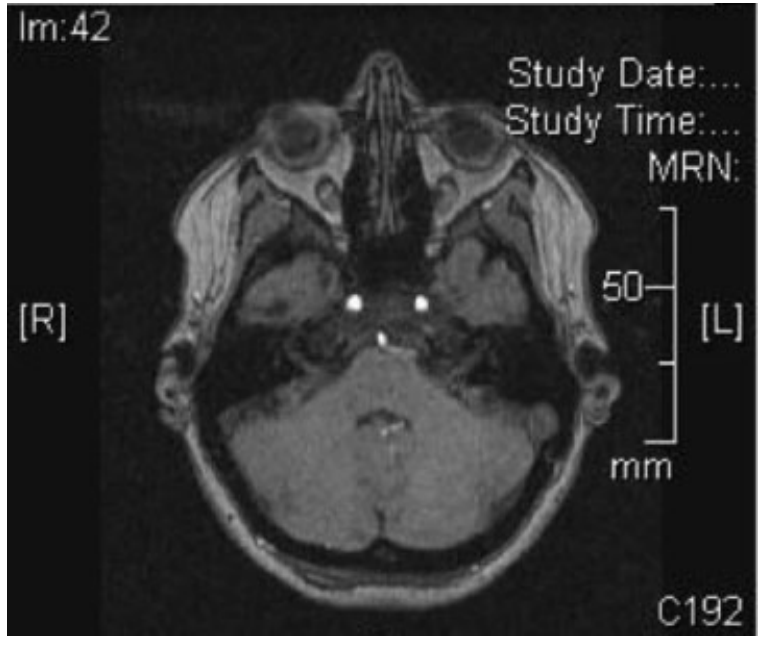

Fig. 1 The preoperative magnetic resonance imaging examination did not show any pathologic findings.

negative influence of the vertigo and tinnitus on her quality of life.

As preparation for a lateral suboccipital retrosigmoidal craniotomy in a semisitting position, the patient underwent a thin layer skull base computed tomography scan and transesophageal echocardiography.

The left retrosigmoid craniotomy (with cranioplasty) was performed in the semisitting position with intraoperative monitoring of the facial and vestibulocochlear nerve (ABR) ( - Fig. 3).

Microsurgical exploration of the vestibulocochlear nerve after drilling the posterior wall of the internal auditory canal (IAC) revealed the AICA entering the internal auditory meatus and looping into the canal for $8 \mathrm{~mm}$, as expected from the MRA, thereby compressing the vestibulocochlear nerve. The AICA contact to the vestibular nerve extended from the porus into the middle part of the IAC. After dissection of the arachnoid

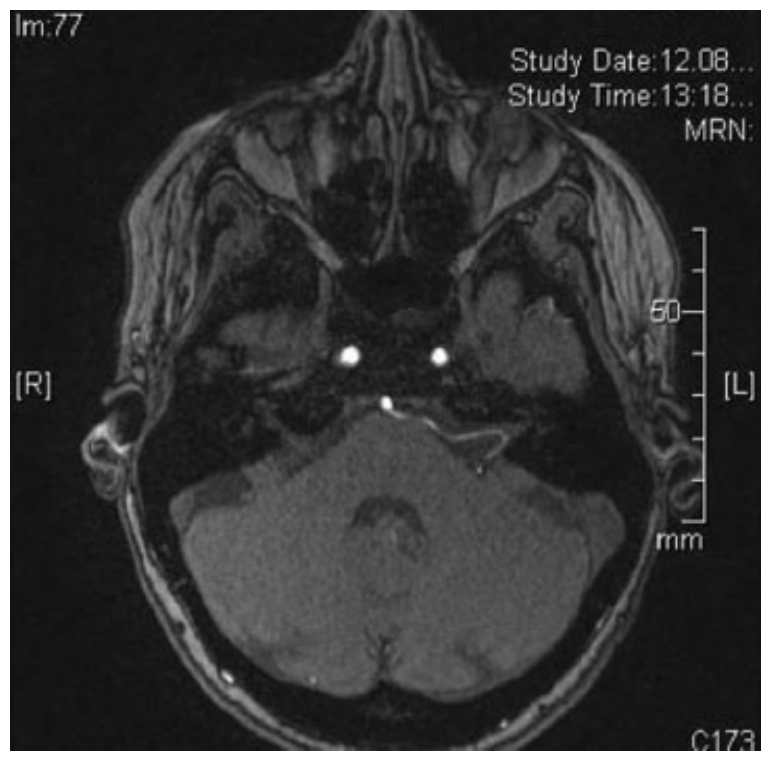

Fig. 2 An additional preoperative magnetic resonance angiography examination revealed a loop of the anterior interior cerebellar artery extending into the left internal auditory meatus. 


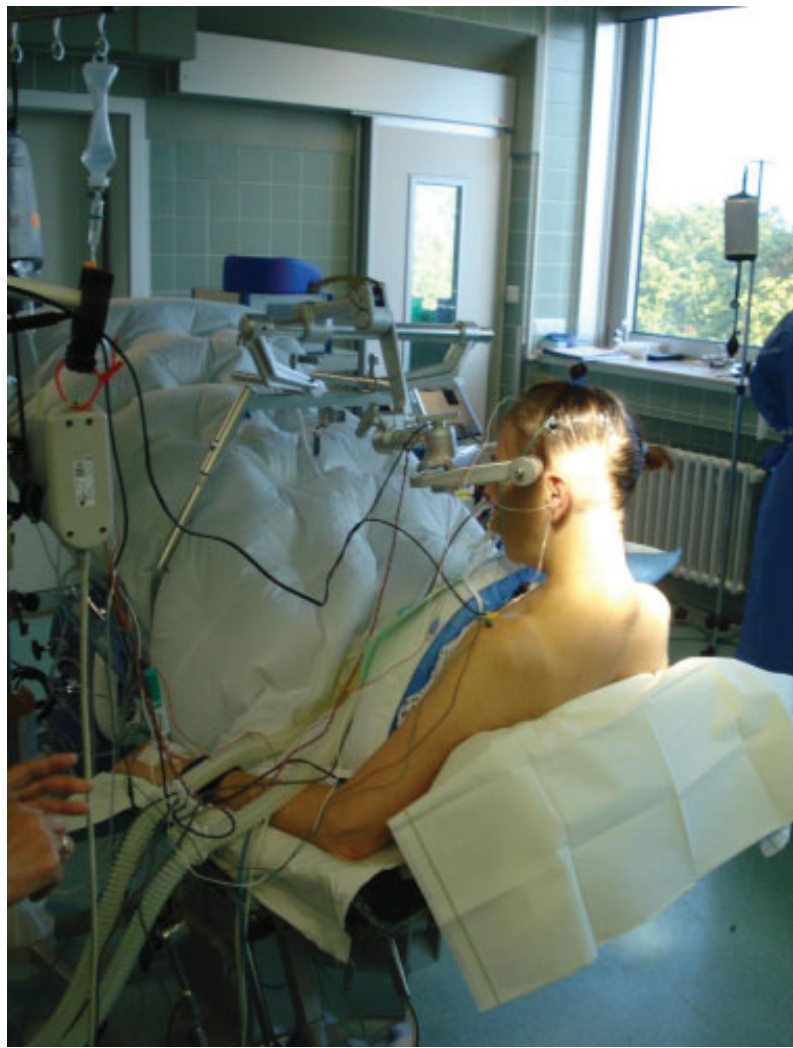

Fig. 3 A left retrosigmoid craniotomy (with cranioplasty) was performed in the semisitting position with intraoperative monitoring of the facial and vestibulocochlear nerve.

membrane, the AICA was gently mobilized from the vestibulocochlear nerve and removed from the IAC into the cerebellopontine angle ( - Fig. 4). Afterward, two pieces of muscle were interposed between the eighth cranial nerve and the AICA.

Finally, the posterior wall of the IAC was closed with muscle and fibrin glue. Facial and ABR monitoring was performed continuously during the surgery and did not show any significant changes compared with the preoperative findings.

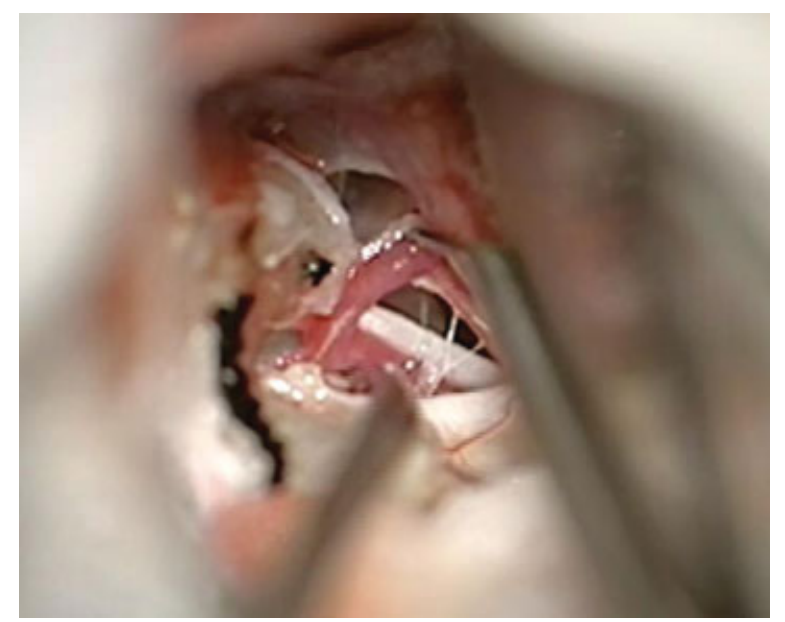

Fig. 4 The intraoperative mobilization of the intrameatal anterior interior cerebellar artery from the internal auditory canal (IAC) after drilling the posterior wall of the IAC.
The postoperative course was uneventful with a complete relief of symptoms. Notably, there was no change in hearing ability at the postoperative audiogram examination (-Fig. 5). The postoperative ABR examination showed completely normal interwave latencies. Follow-up tests were performed six times during the last 2 years without any recurrence of the symptoms or changes in the audiogram examinations. The vestibulocochlear parameters (including the caloric test, posturography, and general balance) were normal during direct postoperative as well as follow-up examinations.

\section{Surgical Considerations}

The labyrinthine artery (auditory artery, internal auditory artery) is a long slender branch of the AICA ( $85-100 \%$ of cases), basilar artery ( $<15 \%$ of cases), or vertebral artery (4.1\%). It arises from the middle of the artery, accompanies the vestibulocochlear nerve through the internal acoustic meatus, and is distributed to the internal ear. ${ }^{12}$

As shown in - Fig. 6, the labyrinthine artery of our patient arose from the intrameatal AICA loop and entered the internal acoustic meatus. During surgery, the AICA should be mobilized and removed from the IAC into the cerebellopontine angle. Any direct or indirect injury to the labyrinthine artery during the mobilization of AICA would result in postoperative hearing loss. ${ }^{13}$ - Fig. 5 shows the pre- and postoperative audiogram.

\section{Discussion}

The anatomical variations of the neurovasculature in the cerebellopontine angle result from the late development of the AICA and the posterior inferior cerebellar artery (PICA) from the primitive lateral basivertebral anastomosis. ${ }^{8,14-17}$ These vascular variations may cause dislocation and compression of the cranial nerves in the posterior cranial fossa.

Over the past decade, neurosurgical clinical and anatomical experience has attributed several symptoms to the microvascular compression of the vestibulocochlear nerve. Several cases of disabling vertigo, tinnitus, hearing loss, and imbalance were noted to be caused by vascular compression of the eighth cranial nerve. ${ }^{3-5}$

However, significant controversy persists among clinicians in the neurotologic diagnosis of neurovascular compression of the eighth cranial nerve. Abnormal ABR, brief spells of vertigo, unilateral sensorineural hearing loss, abnormal vestibular findings, continuous tinnitus, hearing loss, abnormal electronystagmograms, and other findings have been reported to be diagnostic for neurovascular compression of the eighth cranial nerve. ${ }^{18-22}$

Many reports in the literature explain the role of AICA or PICA or their branches, resulting in the microvascular compression of the vestibulocochlear nerve in the cerebellopontine angle that causes symptoms of disabling vertigo, tinnitus, and hearing loss. ${ }^{14,23}$

As a theory, curves and loops of vessels running near the cranial nerves may be created mostly by degenerative alterations of aging, and such vessels can compress surrounding neural elements. ${ }^{24}$ 

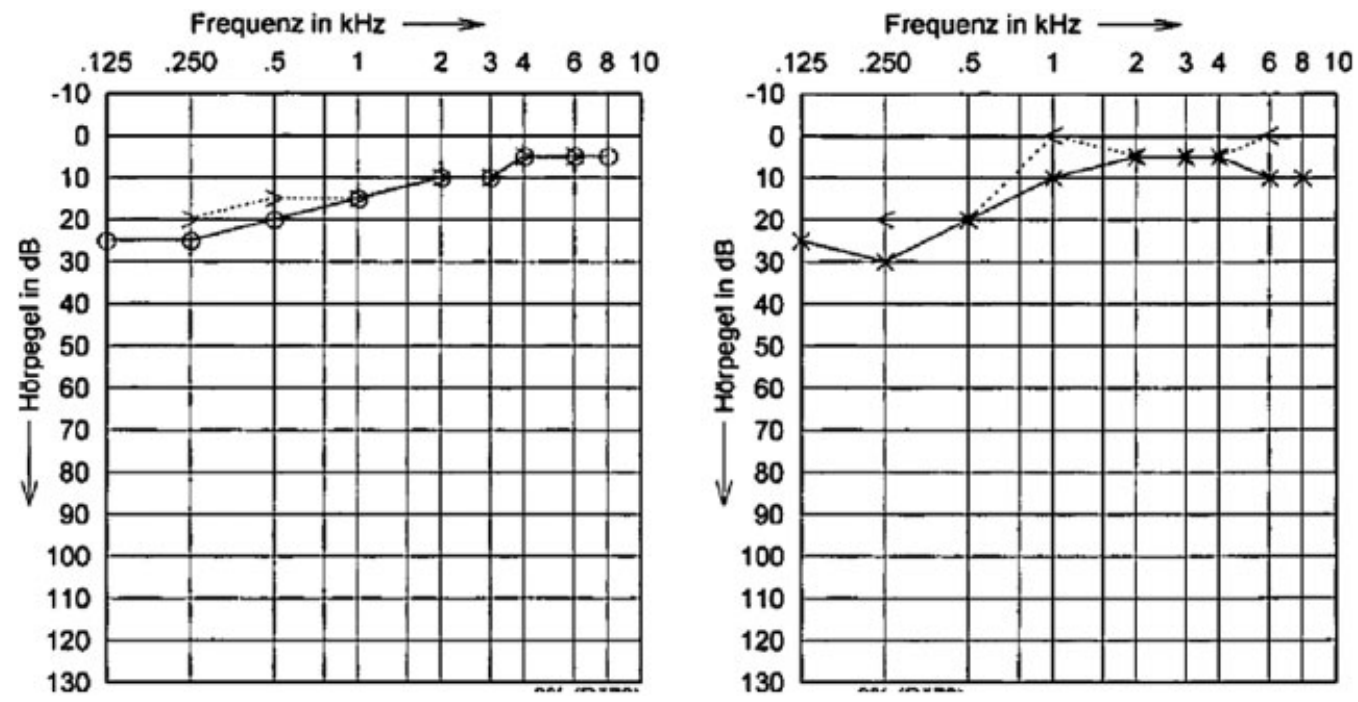

Fig. 5 The preoperative (left) and postoperative (right) audiogram of the patient did not show any hearing loss before or after the operation, respectively.

A

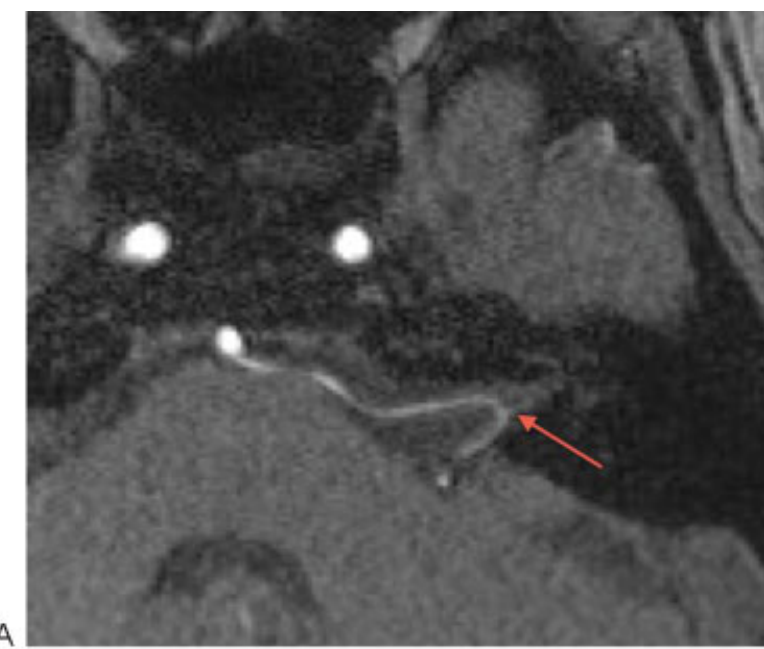

B

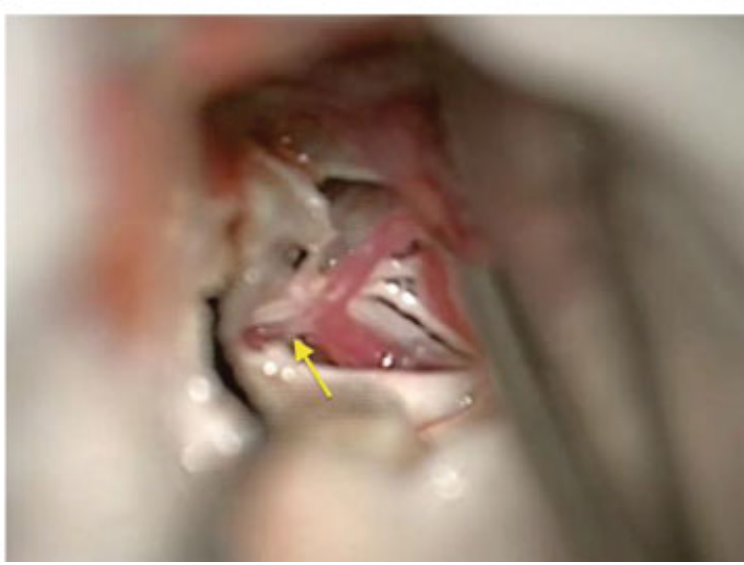

Fig. 6 (A) The preoperative magnetic resonance angiography of the patient shows the labyrinthine artery (red arrow) arising from the anterior interior cerebellar artery (AICA) and entering into the internal auditory canal (IAC). Any injury to this artery results in postoperative hearing loss. (B) The intraoperative image shows the labyrinthine artery (yellow arrow) arising from the AICA and entering the IAC (see Surgical Considerations in the text).
Furthermore, the different results of MVD of the eighth cranial nerve, including the surgical treatment of tinnitus and disabling positional vertigo, have been reported in the literature. ${ }^{4,19,25}$

In 1984, Janetta et al introduced a new term, disabling positional vertigo (DPV), and they identified a group of patients with vestibular disorders whose symptoms were totally relieved by MVD of the eighth nerve. ${ }^{19}$

In 1993, Møller et al reported the results of MVD of the eighth cranial nerve in 207 patients with DPV and reported a cure rate of $80 \%{ }^{4}$

These reports were subsequently supported by numerous studies on vertigo and tinnitus. In 1998, Ryu et al reported the results of neurovascular decompression of the eighth cranial nerve in 43 cases of vertigo and tinnitus, and they established diagnostic criteria and operative indications. They reported a complete recovery or marked improvement of subjective symptoms in $100 \%$ of the patients with vertigo and $65.5 \%$ of the patients with tinnitus. They demonstrated that the symptoms of neurovascular compression of the eighth cranial nerve depend on the part of the nerve compressed by blood vessels. For example, in patients with vertigo and tinnitus, there was vascular compression of the rostroventral and caudal surface of the nerve, respectively. ${ }^{26}$

This review of the literature shows that the neurovascular compression of the vestibulocochlear nerve is usually located in the cerebellopontine angle but not the intrameatal angle.

To the best of our knowledge, only two case reports have presented intrameatal vascular compression as a cause of vestibulocochlear compression syndrome (-Table 1).

Our case along with the two cases just cited adds another avenue to explore in the diagnosis and treatment of vestibulocochlear compression syndrome.

It is still debatable if the exploration of the vestibulocochlear nerve should continue into the IAC if no clear neurovascular conflict in the cerebellopontine angle is found. ${ }^{8}$ Such 
case reports may introduce a new concept to the intrameatal exploration of the vestibulocochlear nerve in such situations.

However, there are articles reporting that the radiologic demonstration of contact between a vascular loop formed by the AICA and the eighth cranial nerve on MRI scans should be considered a normal anatomical finding and should not be used to support the diagnosis of a "vascular compression syndrome." 27,28

Also, MVD of the vestibulocochlear nerve (especially with regard to the improvement of tinnitus) is not always successful. In a study regarding MVD treatment for a selected group of 72 patients with severe tinnitus, Møller and Møller showed that $11 \%$ of patients had only slight improvement, $45.8 \%$ had no improvement, and $2.8 \%$ became worse. They showed that the success of such surgery depends on the duration of symptoms before the operation. 29

The diagnosis of vestibulocochlear compression based on symptoms, signs, and radiologic findings is thus not easy to make. The other common causes of vestibulocochlear compression syndrome must be definitively excluded first.

In addition, the surgery should be done in the hands of an expert surgeon because the indication of such decompression surgery is not really absolute.

\section{Conclusion}

In addition to other common causes, disabling vertigo and tinnitus can rarely be caused by intrameatal vascular compression of the vestibulocochlear nerve and may be treated successfully by MVD.

Because the results of MVD of the vestibulocochlear nerve in the literature are not always acceptable, the other common causes of vestibulocochlear compression syndrome must be excluded before the decision to operate is made.

\section{Disclaimer}

The authors have no conflicts of interest to disclose.

\section{References}

1 Sindou M, Leston J, Decullier E, Chapuis F. Microvascular decompression for primary trigeminal neuralgia: long-term effectiveness and prognostic factors in a series of 362 consecutive patients with clear-cut neurovascular conflicts who underwent pure decompression. J Neurosurg 2007;107(6):1144-1153

2 Miller LE, Miller VM. Safety and effectiveness of microvascular decompression for treatment of hemifacial spasm: a systematic review. Br J Neurosurg 2012;26(4):438-444

3 Noguchi Y, Ohgaki T, Tsunoda A, Komatsuzaki A, Muraoka H. Clinical study in vertiginuous patients suspected of having neurovascular compression syndrome of the eighth cranial nerve. [in Japanese]. Nippon Jibiinkoka Gakkai Kaiho 1997;100(5):492-498

4 Møller MB, Møller AR, Jannetta PJ, Jho HD, Sekhar LN. Microvascular decompression of the eighth nerve in patients with disabling positional vertigo: selection criteria and operative results in 207 patients. Acta Neurochir (Wien) 1993;125(1-4):75-82

5 Brackmann DE, Kesser BW, Day JD. Microvascular decompression of the vestibulocochlear nerve for disabling positional vertigo: the House Ear Clinic experience. Otol Neurotol 2001;22(6):882-887
6 Okamura T, Kurokawa Y, Ikeda N, et al. Microvascular decompression for cochlear symptoms. J Neurosurg 2000;93(3):421-426

7 Papanagiotou P, Grunwald IQ Politi M, Struffert T, Ahlhelm F, Reith W. Vascular anomalies of the cerebellopontine angle. [in German]. Radiologe 2006;46(3):216-222

8 Wuertenberger CJ, Rosahl SK. Vertigo and tinnitus caused by vascular compression of the vestibulocochlear nerve, not intracanalicular vestibular schwannoma: review and case presentation. Skull Base 2009;19(6):417-424

9 Yasuoka S, Takakura K, Fukaya T. Case of tinnitus, vertigo, and a loss of caloric response due to neurovascular compression. [in Japanese]. No To Shinkei 1983;35(11):1097-1101

10 De Ridder D, De Ridder L, Nowé V, Thierens H, Van de Heyning P, Møller A. Pulsatile tinnitus and the intrameatal vascular loop: why do we not hear our carotids? Neurosurgery 2005;57(6): 1213-1217; discussion 1213-1217

11 Michel O, Jahns T, Joost-Enneking M, Neugebauer P, Streppel M, Stennert E. The Stennert antiphlogistic-rheologic infusion schema in treatment of cochleovestibular disorders. [in German]. HNO 2000;48(3):182-188

12 Zhang K, Wang F, Zhang Y, Li M, Shi X. Anatomic investigation of the labyrinthine artery. [in Chinese]. Zhonghua Er Bi Yan Hou Ke Za Zhi 2002;37(2):103-105

13 Lee H, Sohn SI, Jung DK, et al. Sudden deafness and anterior inferior cerebellar artery infarction. 2002;33(12):2807-2812

14 Kim HN, Kim YH, Park IY, Kim GR, Chung IH. Variability of the surgical anatomy of the neurovascular complex of the cerebellopontine angle. Ann Otol Rhinol Laryngol 1990;99(4 Pt 1):288-296

15 Martin RG, Grant JL, Peace D, Theiss C, Rhoton AL Jr. Microsurgical relationships of the anterior inferior cerebellar artery and the facialvestibulocochlear nerve complex. Neurosurgery 1980;6(5):483-507

16 Padget $\mathrm{D}$. The development of the cranial arteries in the human embryo. Contrib Embryol 1948;32:207-261

17 Rhoton AL Jr. Microsurgical anatomy of the posterior fossa cranial nerves. Clin Neurosurg 1979;26:398-462

18 Jannetta PJ. Neurovascular cross-compression in patients with hyperactive dysfunction symptoms of the eighth cranial nerve. Surg Forum 1975;26:467-469

19 Jannetta PJ, Møller MB, Møller AR. Disabling positional vertigo. N Engl J Med 1984;310(26):1700-1705

20 Lesinski SG, Chambers AA, Komray R, Keiser M, Khodadad G. Why not the eighth nerve? Neurovascular compression-probable cause for pulsatile tinnitus. Otolaryngol Head Neck Surg (1979) 1979;87(1):89-94

21 McCabe BF, Harker LA. Vascular loop as a cause of vertigo. Ann Otol Rhinol Laryngol 1983;92(6 Pt 1):542-543

22 Møller MB. Results of microvascular decompression of the eighth nerve as treatment for disabling positional vertigo. Ann Otol Rhinol Laryngol 1990;99(9 Pt 1):724-729

23 Bachor E, Selig YK, Jahnke K, Rettinger G, Karmody CS. Vascular variations of the inner ear. Acta Otolaryngol 2001;121(1):35-41

24 Kuncz A, Vörös E, Barzó P. Vascular compression syndromes of the cranial nerves. [in Hungarian]. Ideggyogy Sz 2011;64(1-2): 6-13

25 Eide PK, Slettebø H. Vascular compression and cranial nerve diseases. [in Norwegian]. Tidsskr Nor Laegeforen 1998;118(26):4079-4084

26 Ryu H, Yamamoto S, Sugiyama K, Nishizawa S, Nozue M. Neurovascular compression syndrome of the eighth cranial nerve. Can the site of compression explain the symptoms? Acta Neurochir (Wien) 1999;141(5):495-501

27 Makins AE, Nikolopoulos TP, Ludman C, O'Donoghue GM. Is there a correlation between vascular loops and unilateral auditory symptoms? Laryngoscope 1998;108(11 Pt 1):1739-1742

28 Parnes LS, Shimotakahara SG, Pelz D, Lee D, Fox AJ. Vascular relationships of the vestibulocochlear nerve on magnetic resonance imaging. Am J Otol 1990;11(4):278-281

29 Møller AR, Møller MB. Microvascular decompression operations. Prog Brain Res 2007;166:397-400 